\title{
New insights into a bacterial metabolic and detoxifying association responsible for the mineralization of the thiocarbamate herbicide molinate
}

\author{
Luisa Barreiros, ${ }^{1,2}$ Ana Fernandes, ${ }^{1}$ António C. Silva Ferreira, ${ }^{2}$ \\ Helena Pereira, ${ }^{3}$ Margarida M. S. M. Bastos, ${ }^{1}$ Célia M. Manaia ${ }^{2}$ \\ and Olga C. Nunes ${ }^{1}$ \\ ${ }^{1}$ LEPAE - Departamento de Engenharia Química, Faculdade de Engenharia, Universidade do Porto, \\ 4200-465 Porto, Portugal \\ ${ }^{2}$ Escola Superior de Biotecnologia, Universidade Católica Portuguesa, 4200-072 Porto, Portugal \\ ${ }^{3}$ Instituto de Tecnologia Química e Biológica, Av. da República - EAN, 2780-157 Oeiras, Portugal
}

Correspondence

Olga C. Nunes

opnunes@fe.up.pt

Received 22 November 2007

Revised 30 December 2007

Accepted 2 January 2008

\begin{abstract}
A novel pathway of molinate mineralization promoted by a defined mixed culture composed of five bacteria (named ON1 to ON5) was proposed previously. Evidence was obtained of a metabolic association between Gulosibacter molinativorax $\mathrm{ON} 4^{\top}$, capable of molinate breakdown, and the remaining bacteria. In the present study, the role of each isolate in that metabolic association was further explored and the possible synergistic effect of all the bacterial isolates for the stability of the mixed culture is discussed. The cleavage of the molinate thioester bond, whether occurring under aerobic or anaerobic conditions, releases ethanethiol ( $S$-ethyl moiety) and an azepane moiety derivative, identified as azepane-1-carboxylic acid. This azepane moiety is degraded, in the presence of oxygen, by Pseudomonas strains ON1 and ON3 and G. molinativorax $\mathrm{ON} 4^{\top}$. Ethanethiol, which inhibits G. molinativorax $\mathrm{ON}^{\top}{ }^{\top}$, is consumed by Pseudomonas strain ON1 and Stenotrophomonas maltophilia ON2. Although a two-member mixed culture of G. molinativorax $\mathrm{ON} 4^{\top}$ and Pseudomonas strain $\mathrm{ON} 1$ was able to promote the aerobic mineralization of molinate, after 20 successive transfers of the five-member mixed culture in mineral medium with molinate, none of these isolates were lost. The results obtained indicate that the whole mixed culture may have a higher fitness than the two-member culture, even when the basic degradative and cross-protection functions are assured.
\end{abstract}

\section{INTRODUCTION}

In nature, micro-organisms live in communities with different levels of complexity in terms of phylogenetic and metabolic diversity. In these communities, the stable coexistence of the micro-organisms results from different types of interaction, leading its members to function as a biological unit (Pelz et al., 1999; Kato et al., 2005). External perturbations, such as the introduction of large quantities of xenobiotics into the environment, create strong selective pressures. One expected reaction to such a stimulus is the establishment of communities able to degrade these compounds. The elucidation of the contribution of individual members of a microbial community to metabolic degradative

Abbreviations: ACA, azepane-1-carboxylic acid; DGGE, denaturing gradient gel electrophoresis; DOC, dissolved organic carbon; HMl, hexamethyleneimine; HMOC, heteronuclear multiple quantum coherence; SPME-GC-FID, solid-phase micro-extraction-gas chromatography-flame ionization detection. pathways may shed light on the biochemical transformations taking place and on the interrelationships responsible for the stable coexistence of the organisms. Several studies reporting co-operation among consortium members during the degradation of pollutants have shown different modes of microbial interaction. The literature available shows that the distribution of metabolic steps among consortium members may rely upon different forms of association, namely crossfeeding (e.g. De Souza et al., 1998; Dejonghe et al., 2003), detoxification (e.g. Feigel \& Knackmuss, 1993; Pelz et al., 1999) or supply of nutritional requirements (e.g. Hay et al., 2001; Sorensen et al., 2002).

The study of the evolution of degradative pathways has been another area of interest, encouraged by the need to deal with environmental contamination with xenobiotics. Some evidence suggests that an original metabolic association of various micro-organisms may evolve to a single-organism-based process (e.g. De Souza et al., 1998). Such a transformation 
can be explained on the basis of horizontal gene transfer, leading to the assembly of different catabolic mobile genetic elements in a single cell. The origination of new catabolic routes by the rearrangement and combination of pre-existing genes of different micro-organisms has been reported (Tsuda et al., 1999; Top et al., 2002; Nojiri et al., 2004). Thus, the description of metabolic pathways before the occurrence of horizontal transfer of catabolic genes may provide insights into the evolution of microbial degradation of xenobiotic compounds.

In a previous report (Barreiros et al., 2003) we showed that a defined mixed culture composed of five bacterial isolates (mixed culture DC) could mineralize the herbicide molinate without the accumulation of degradation products. Isolates ON1 and ON3 were identified as Pseudomonas chlororaphis and Pseudomonas nitroreducens, respectively, isolate ON2 as Stenotrophomonas maltophilia and isolate ON5 as Achromobacter xylosoxidans; isolate ON4, not affiliated to any validly named taxon, represented a new genus and species, Gulosibacter molinativorax, within the family Microbacteriaceae (Manaia et al., 2004). In mixed culture DC, G. molinativorax $\mathrm{ON} 4^{\mathrm{T}}$ was able to degrade molinate into ethanethiol and another compound that could not be detected but that was presumed to be an azepane derivative of the herbicide (Barreiros et al., 2003). In spite of this degradative activity, G. molinativorax $\mathrm{ON} 4^{\mathrm{T}}$ was not able to grow in axenic culture with molinate at concentrations above $2 \mathrm{mM}$, an effect that was abolished when the Gram-negative members of the mixed culture were grown in a vial placed in the headspace of the growth vessel. This observation, along with the monitoring of sulphur compounds (ethanethiol and diethyl disulphide) formed in the headspace of the axenic but not in the mixed culture, suggested a detoxifying association between G. molinativorax $\mathrm{ON}^{\mathrm{T}}$ and its commensals. In this study, the fate of the azepane derivative and the role of each of the five members of culture DC in molinate mineralization were further investigated.

\section{METHODS}

Chemicals. Molinate (azepan-1-yl-ethylsulphanylmethanone, $\mathrm{C}_{9} \mathrm{H}_{17} \mathrm{NOS}$ ) of $97 \%$ purity was obtained from Herbex, Produtos Químicos (Estoril, Portugal). Ethanethiol $\left(\mathrm{C}_{2} \mathrm{H}_{6} \mathrm{~S}\right)$, diethyl disulphide $\left(\mathrm{C}_{4} \mathrm{H}_{10} \mathrm{~S}_{2}\right)$, ethyl methyl sulphide $\left(\mathrm{C}_{3} \mathrm{H}_{8} \mathrm{~S}\right)$, hexamethyleneimine (HMI) $\left(\mathrm{C}_{6} \mathrm{H}_{13} \mathrm{~N}\right)$, caprolactam $\left(\mathrm{C}_{6} \mathrm{H}_{11} \mathrm{NO}\right)$ and 6-aminohexanoic acid $\left(\mathrm{C}_{6} \mathrm{H}_{13} \mathrm{NO}_{2}\right)$ were obtained from Sigma-Aldrich. All other reagents were analytical grade from commercial sources.

Growth media and culture conditions. Culture DC and isolates ON1-ON5 were grown, in axenic or defined mixed cultures, in mineral medium B (Barreiros et al., 2003) supplemented with molinate or other substrate, at $30{ }^{\circ} \mathrm{C}$ and 120 r.p.m. Inocula of culture DC were grown in medium $\mathrm{B}$ with $4 \mathrm{mM}$ molinate and those of axenic cultures were grown on Luria-Bertani medium (LB) with agar ( $2 \% \mathrm{w} / \mathrm{v})$, supplemented with $1 \mathrm{mM}$ molinate (modified LA) to maintain the selective pressure in the medium.

The anaerobic degradation of molinate by $G$. molinativorax $\mathrm{ON} 4^{\mathrm{T}}$ and by culture DC was assayed in $100 \mathrm{ml}$ PTFE-sealed flasks containing $75 \mathrm{ml}$ medium B supplemented with $1 \mathrm{mM}$ molinate and $0.01 \%$ $(\mathrm{w} / \mathrm{v})$ potassium nitrate, and incubated under a nitrogen atmosphere for 15 days. Samples were collected over time and were analysed for biomass, molinate, dissolved organic carbon (DOC) and ethanethiol contents.

The ability of each member of culture DC to use the azepane moiety derivative azepane-1-carboxylic acid (ACA) resulting from molinate degradation was assessed by incubating each individual organism in the cell-free liquid phase of anaerobic resting cells of $G$. molinativorax $\mathrm{ON} 4^{\mathrm{T}}$. ACA was produced by incubating resting cells of G. molinativorax $\mathrm{ON} 4^{\mathrm{T}}$ in sterile saline solution supplemented with $2 \mathrm{mM}$ molinate, under a nitrogen atmosphere, at $30{ }^{\circ} \mathrm{C}$ and 120 r.p.m. for $12 \mathrm{~h}$, as described below. The suspension was centrifuged $(15500 \mathrm{~g}, 10 \mathrm{~min})$; the supernatant was filter-sterilized $(0.2 \mu \mathrm{m}$ pore size $)$ and supplemented with medium B components and magnesium sulphate $(0.4 \mathrm{mM})$ as a sulphur source. Growth was monitored over 7 days.

The ability of culture DC and its members to use different substrates as carbon and nitrogen sources was tested in medium B supplemented with $0.4 \mathrm{mM}$ magnesium sulphate and $5.5 \mathrm{mM} \mathrm{HMI}$, caprolactam or 6 -aminohexanoic acid. When necessary, the medium was supplemented with $4 \mathrm{mM}$ ammonium sulphate (as nitrogen source) or with $0.2 \mathrm{~g}$ yeast extract $\mathrm{l}^{-1}$ (as source of growth factors). Cultures were incubated aerobically in $100 \mathrm{ml}$ screw-capped Erlenmeyer flasks with Teflon-lined caps. Cell growth was monitored over 7 days.

To compare the molinate mineralization efficiency of culture DC and of the mixture of $P$. chlororaphis $\mathrm{ON} 1$ and G. molinativorax $\mathrm{ON} 4^{\mathrm{T}}$, these cultures were grown aerobically in $100 \mathrm{ml}$ PTFE-sealed flasks containing $20 \mathrm{ml}$ medium B with $4 \mathrm{mM}$ molinate. Culture samples were collected at regular intervals and analysed for biomass, molinate and DOC contents. The presence of molinate $S$-ethyl and azepane moieties was also analysed, in the headspace (SPME-GC-FID) and in the liquid phase of cultures (NMR), respectively. An axenic culture of G. molinativorax $\mathrm{ON} 4^{\mathrm{T}}$ and uninoculated medium were analysed similarly, as controls.

To assess the stability of mixed culture DC, cells were grown in medium B with $4 \mathrm{mM}$ molinate for 5 days at $30{ }^{\circ} \mathrm{C}$, stored at $4{ }^{\circ} \mathrm{C}$ for $8-20$ days, transferred to fresh medium and incubated for a further 5 days at $30{ }^{\circ} \mathrm{C}$. Culture composition was assessed by PCR-denaturing gradient gel electrophoresis (DGGE) after a total of 20 successive culture transfers.

Resting cell assays. The isolates were grown on modified LA medium at $30^{\circ} \mathrm{C}$, for 1 or 3 days, centrifuged, washed and resuspended in phosphate buffer $54 \mathrm{mM}$, pH $7.2(\mathrm{~PB})$, supplemented with the substrate to test. For NMR analysis, PB was replaced by $50 \mathrm{mM} \mathrm{NaCl}$. Cell densities corresponding to $4 \mathrm{~g}$ cell dry weight $\mathrm{l}^{-1}$ were used in all assays. To evaluate the ability of each isolate to consume ethanethiol, resting cell assays were performed in $\mathrm{PB}$ supplemented with $0.4 \mathrm{mM}$ of this sulphur compound. Resting cells of culture DC were used as positive control and uninoculated buffer with ethanethiol was used to assess abiotic losses. Sulphur compound content was measured in the headspace (SPME-GC-FID). To obtain and/or identify the azepane derivative, resting cells of G. molinativorax $\mathrm{ON} 4^{\mathrm{T}}$ were incubated in saline solution supplemented with $2 \mathrm{mM}$ molinate under a nitrogen atmosphere, at $30{ }^{\circ} \mathrm{C}$ and 120 r.p.m. Samples were collected over time and the liquid phase was analysed for molinate content (HPLC) or for detection and identification of molinate metabolites (NMR).

To evaluate if the use of HMI and caprolactam by G. molinativorax $\mathrm{ON} 4^{\mathrm{T}}$ were induced processes, resting cells pregrown with $2 \mathrm{mM}$ of the azepane moiety derivative of molinate (ACA) were incubated in PB with $2 \mathrm{mM} \mathrm{HMI}$ and/or caprolactam. Abiotic losses were assessed in uninoculated buffer with the same concentration of HMI and/or caprolactam. Samples were collected over time and analysed by NMR or HPLC to follow HMI or caprolactam degradation, respectively. Pseudomonas strains ON1 and ON3 were also tested for ACA-HMI induction of caprolactam degradation, using the same procedure. 
Analytical procedures. Cell growth was monitored spectrophotometrically $\left(\mathrm{OD}_{610}\right.$; Philips PU-8620UV/VIS spectrophotometer) and cell dry weight was obtained via a calibration curve (Barreiros et al., 2003). Molinate and DOC contents in culture supernatants were analysed (HPLC and total organic carbon) as described before (Barreiros et al., 2003). Ethanethiol was quantified in the liquid phase using the colorimetric method described by Dias \& Weimer (1998). The analysis of ethanethiol, diethyl disulphide and ethyl methyl sulphide in the headspace of cultures or resting cells assays was performed by SPME-GC-FID as described by Barreiros et al. (2003).

NMR analysis. Proton spectra were recorded on Bruker DRX500 or AMX300 spectrometers operating, respectively, at $500.13 \mathrm{MHz}$ and $300.13 \mathrm{MHz}$ for ${ }^{1} \mathrm{H}$, equipped with $5 \mathrm{~mm}$ diameter inverse detection broadband probe heads (with and without $X Y Z$ gradients). In both cases water pre-saturation was applied. Acquisition parameters on DRX500: spectral width, $10 \mathrm{kHz}$; pulse width, $7 \mathrm{~ms}\left(60^{\circ} \mathrm{flip}\right.$ angle $)$; data points, 64K; repetition delay, $1 \mathrm{~s}$; number of transients, 100. Acquisition parameters on AMX300: spectral width, $5 \mathrm{kHz}$; pulse width, $4 \mathrm{~ms}\left(70^{\circ}\right.$ flip angle); data points, $16 \mathrm{~K}$; repetition delay, $1.5 \mathrm{~s}$; number of transients, 100. Carbon spectra were recorded on a Bruker DRX500 operating at $125.77 \mathrm{MHz}$ for ${ }^{13} \mathrm{C}$ and equipped with a ${ }^{1} \mathrm{H} /{ }^{13} \mathrm{C}$ dualprobe head ( $5 \mathrm{~mm}$ diameter). Acquisition parameters: spectral width, $31.5 \mathrm{kHz}$; pulse width, $6 \mathrm{~ms}$ ( $70^{\circ}$ flip angle); data points, $64 \mathrm{~K}$; repetition delay, $10 \mathrm{~s}$; number of transients, 5500. Proton broadband decoupling was applied during acquisition time only (1.04 s). All the spectra were acquired at a constant temperature of $27{ }^{\circ} \mathrm{C}$. Chemical shifts were referenced to tetramethylsilane at 0.0 p.p.m. $\left({ }^{1} \mathrm{H}\right)$ and methanol at 49.3 p.p.m. $\left({ }^{13} \mathrm{C}\right)$, used as external references.

Denaturing gradient gel electrophoresis. Total genomic DNA was extracted based on the method described by Cashion et al. (1977) from $0.35 \mathrm{mg}$ biomass of culture DC or of each isolate. A $200 \mathrm{bp}$ fragment (based on the reference strain Escherichia coli bases 338 and 518) of the $16 \mathrm{~S}$ rRNA gene was amplified using the bacterial $16 \mathrm{~S}$ rDNA primers forward 338F_GC, containing a GC clamp (5' -CGC CCG CCG CGC GCG GCG GGC GGG GCG GGG GCA CGG GGG GAC TCC TAC GGG AGG CAG CAG-3'), and reverse 518R (5'-ATT ACC GCG GCT GCT GG-3') (Muyzer et al., 1993). Reaction mixtures $(50 \mu \mathrm{l})$ were prepared as described by Henriques et al. (2006). The PCR conditions were: $5 \mathrm{~min}$ at $94{ }^{\circ} \mathrm{C}, 30$ cycles of $\left(30 \mathrm{~s}\right.$ at $92{ }^{\circ} \mathrm{C}, 30 \mathrm{~s}$ at $55^{\circ} \mathrm{C}, 30 \mathrm{~s}$ at $\left.72{ }^{\circ} \mathrm{C}\right)$, and $7 \mathrm{~min}$ at $72{ }^{\circ} \mathrm{C}$. PCR products were separated in a $8 \%(\mathrm{w} / \mathrm{v})$ polyacrylamide gel with a denaturing gradient ranging from 30 to $55 \%$ (where $100 \%$ denaturant contained $7 \mathrm{M}$ urea and $40 \%$ formamide), running initially at $20 \mathrm{~V}$ for $20 \mathrm{~min}$, and then at $200 \mathrm{~V}$ for $5.5 \mathrm{~h}$ at $60{ }^{\circ} \mathrm{C}$. DGGE bands corresponding to each culture DC isolate were excised from the gel, eluted with $20 \mu \mathrm{l}$ ultrapure water, reamplified by PCR with the same primers, cleaned (GFX PCR DNA and Gel Band Purification kit, Amersham Biosciences) and subsequently sequenced with primer 518R. The sequences were determined using a model ABI 3700 DNA analyser (Applied Biosystems), and their quality was checked manually using the BioEdit software (Hall, 1999). These sequences were compared with those obtained for the 16S rRNA gene of each isolate (accession numbers: $P$. chlororaphis ON1, AJ306832; S. maltophilia ON2, AJ306833; $P$. nitroreducens ON3, AJ306834; G. molinativorax $\mathrm{ON}^{\mathrm{T}}$, AJ306835; A. xylosoxidans ON5, AJ306836).

Kinetic models. Specific cell growth and molinate degradation rates were calculated during the exponential growth phase according to the first-order kinetic model described by Barreiros et al. (2003). The same data were fitted to the Haldane equation:

$\mu=\frac{\mu_{\mathrm{max}} S}{K_{\mathrm{s}}+S+\frac{S^{2}}{K_{\mathrm{i}}}}$

where $\mu$ and $\mu_{\max }$ are, respectively, the specific and the maximum specific growth rates, $S$ is the molinate concentration, and $K_{\mathrm{s}}$ and $K_{\mathrm{i}}$ are the saturation and inhibition constants, respectively.

\section{RESULTS AND DISCUSSION}

\section{Identification of the azepane moiety derivative of molinate}

In order to gain new insights into the complete mineralization of molinate by mixed culture DC, the azepane moiety derivative originated by the cleavage of molinate by $G$. molinativorax $\mathrm{ON} 4^{\mathrm{T}}$ was identified. In previous studies this ring moiety could not be detected, a fact that was explained on the basis of its possible rapid use, as a carbon and/or nitrogen source, by G. molinativorax $\mathrm{ON} 4^{\mathrm{T}}$ and, eventually, other members of the mixed culture (Barreiros et al., 2003). However, the limitation of the growth conditions and analytical methods (HPLC and GC-MS) used could also hamper the detection of the azepane moiety. In fact, it was observed that under anaerobic conditions mixed culture DC degraded $90 \%(\mathrm{w} / \mathrm{w})$ of the added molinate, whereas only $28 \%$ of the dissolved organic carbon (DOC) was consumed after $80 \mathrm{~h}$ of incubation (Correia et al., 2006). These data suggested the accumulation of the molinate azepane moiety, although it could not be detected by HPLC or GC-MS. Therefore, it was hypothesized that, in the absence of oxygen, the hydrolysis of the molinate thioester bond could occur as long as G. molinativorax $\mathrm{ON}^{\mathrm{T}}$ was viable, although the further degradation of the metabolites was not possible. This hypothesis was tested by culturing mixed culture DC and G. molinativorax $\mathrm{ON} 4^{\mathrm{T}}$ anaerobically. Under this condition, mixed culture DC was not able to grow, although the herbicide, at an initial concentration of $\sim 160 \mathrm{mg} \mathrm{l}^{-1}$, was slowly degraded to concentrations below the detection limit $\left(0.9 \mathrm{mg} \mathrm{l}^{-1}\right)$. Ethanethiol, a major product of molinate breakdown by $G$. molinativorax $\mathrm{ON} 4{ }^{\mathrm{T}}$, was not detected in the medium. In spite of this, after 15 days of incubation the initial DOC content was reduced by only $30 \%$ (Table 1 ). In a parallel experiment, G. molinativorax $\mathrm{ON}^{\mathrm{T}}$ showed different results: only $45 \%(\mathrm{w} / \mathrm{w})$ of the molinate was degraded; ethanethiol accumulated in the medium $\left(18 \mathrm{mg} \mathrm{l}^{-1}\right.$ in the liquid phase), and the initial DOC content was reduced by only $12 \%$ (Table 1). These final DOC values were consistent with those that would result from partial molinate hydrolysis. These results suggest that under anaerobic conditions $G$. molinativorax $\mathrm{ON} 4^{\mathrm{T}}$ maintains its ability to break down the molinate thioester bond. Apparently, none of the mixed culture DC members is able to further metabolize the azepane derivative that accumulates in the medium. In contrast, ethanethiol was consumed by the Gram-negative isolates of mixed culture DC. Thus, the toxic effect of that thiol on G. molinativorax $\mathrm{ON} 4^{\mathrm{T}}$ was attenuated and it was able to proceed with molinate hydrolysis.

The findings obtained with anaerobic cultures gave a good hint to proceed with the characterization of the azepane moiety. Thus, the anaerobic degradation of molinate by resting cells of $G$. molinativorax $\mathrm{ON} 4^{\mathrm{T}}$ was followed by 
Table 1. Anaerobic degradation of molinate by G. molinativorax $\mathrm{ON} 4^{\top}$ and mixed culture $\mathrm{DC}$ grown in mineral medium $\mathrm{B}$ with molinate

HPLC detection limit of $0.9 \mathrm{mg}^{-1}$ for molinate; colorimetric method detection limit of $0.9 \mathrm{mg}^{-1}$ for ethanethiol; ND, Not determined.

\begin{tabular}{|c|c|c|c|c|c|c|c|c|c|c|}
\hline \multirow[t]{2}{*}{ Culture } & \multicolumn{3}{|c|}{0 days } & \multicolumn{3}{|c|}{7 days } & \multicolumn{4}{|c|}{15 days } \\
\hline & $\begin{array}{l}\text { Cell dry } \\
\text { weight } \\
\left(\mathrm{mg} \mathrm{l}^{-1}\right)\end{array}$ & $\begin{array}{c}\text { Molinate } \\
\left(\mathrm{mg} \mathrm{l}^{-1}\right)\end{array}$ & $\begin{array}{c}\text { DOC } \\
\left(\mathrm{mg} \mathrm{l}^{-1}\right)\end{array}$ & $\begin{array}{l}\text { Cell dry } \\
\text { weight } \\
\left(\mathrm{mg} \mathrm{l}^{-1}\right)\end{array}$ & $\begin{array}{l}\text { Molinate } \\
\left(\mathrm{mg} \mathrm{l}^{-1}\right)\end{array}$ & $\begin{array}{c}\text { DOC } \\
\left(\mathrm{mg} \mathrm{l}^{-1}\right)\end{array}$ & $\begin{array}{l}\text { Cell dry } \\
\text { weight } \\
\left(\mathrm{mg} \mathrm{l}^{-1}\right)\end{array}$ & $\begin{array}{l}\text { Molinate } \\
\left(\mathrm{mg} \mathrm{l}^{-1}\right)\end{array}$ & $\begin{array}{c}\text { DOC } \\
\left(\mathrm{mg} \mathrm{l}^{-1}\right)\end{array}$ & $\begin{array}{c}\text { Ethanethiol } \\
\left(\mathrm{mg} \mathrm{l}^{-1}\right)\end{array}$ \\
\hline G. molinativorax $\mathrm{ON} 4^{\mathrm{T}}$ & 35 & 167 & 121 & 26 & 73 & 110 & 7 & 75 & 106 & 18 \\
\hline Culture DC & 39 & 156 & 117 & 33 & 12 & 101 & 25 & $<0.9$ & 82 & $<0.9$ \\
\hline $\begin{array}{l}\text { Uninoculated medium } \\
\text { with } 1 \mathrm{mM} \text { ethanethiol }\end{array}$ & - & - & ND & - & - & ND & - & - & ND & 18 \\
\hline
\end{tabular}

${ }^{1} \mathrm{H}-\mathrm{NMR}$ (Fig. 1). During incubation, the resonances assigned to molinate (-S- $\mathrm{CH}_{2} \mathrm{CH}_{3}$ at 1.20 p.p.m.; $-\mathrm{S}-\mathrm{CH}_{2} \mathrm{CH}_{3}$ at 2.82 p.p.m.; azepane ring at $3.47,1.70,1.63$ and $1 . \overline{48}$ p.p.m.) decreased and the formation of a product attributed to the molinate azepane moiety was observed. Small amounts of free ethanethiol remained in solution and were detected (HS$\mathrm{CH}_{2} \underline{\mathrm{CH}}_{3}$ at 1.12 p.p.m.; $\mathrm{HS}-\mathrm{CH}_{2} \mathrm{CH}_{3}$ at 3.60 p.p.m.). After

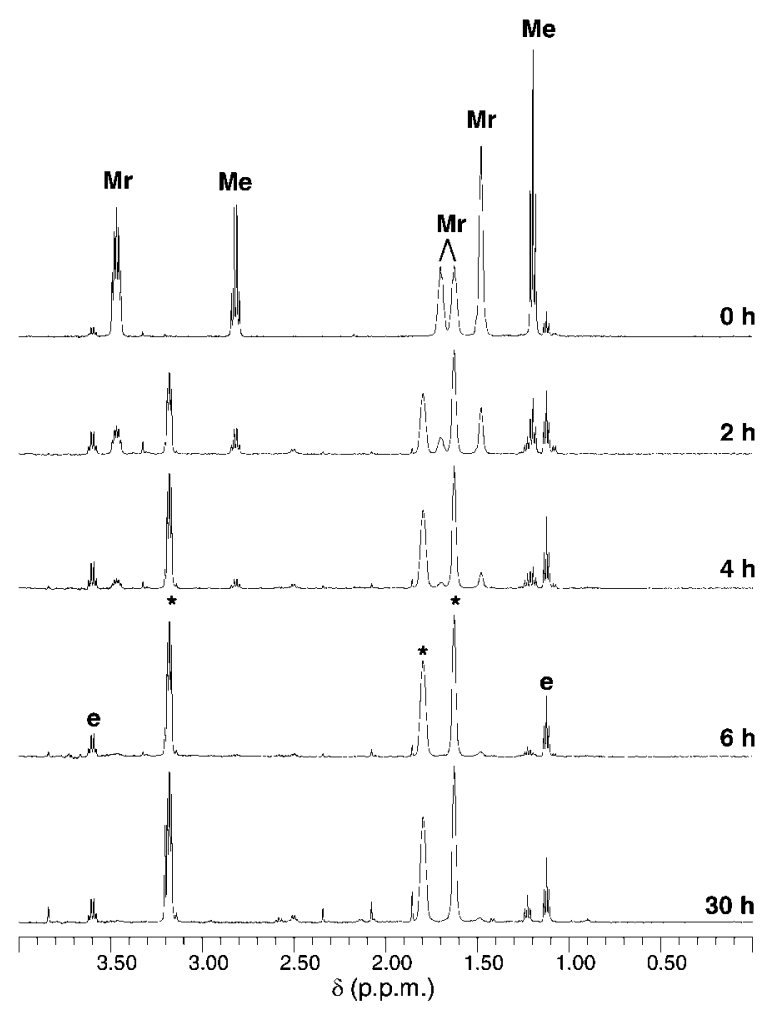

Fig. 1. ${ }^{1} \mathrm{H}-\mathrm{NMR}$ spectra of the liquid phase of resting cells of $\mathrm{G}$. molinativorax $\mathrm{ON} 4{ }^{\top}$ in $50 \mathrm{mM} \mathrm{NaCl}$ solution with molinate $(2 \mathrm{mM})$, under anaerobic conditions. Assignment of the observed resonances: Mr, molinate azepane ring; Me, molinate $S$-ethyl group; e, ethanethiol; *, new anaerobic end product.
$6 \mathrm{~h}$ incubation, all the molinate was converted into degradation products that were not further modified, even after $30 \mathrm{~h}$ incubation. This procedure proved to be a good process to obtain high amounts of the azepane-containing compound and, hence, to proceed with its characterization by ${ }^{1} \mathrm{H}$ and ${ }^{13} \mathrm{C}$ NMR (Fig. 2a, b). ${ }^{1} \mathrm{H}$ and ${ }^{13} \mathrm{C}-\mathrm{NMR}$ chemical shifts characteristic of the new compound, identified as azepane-1-carboxylic acid (ACA), observed in saline solution $(50 \mathrm{mM} \mathrm{NaCl})$ at physiological $\mathrm{pH}$ are indicated in Table 2 . In Fig. 2(a), resonances in the proton spectrum are shifted to the low-field region due to ionic strength of the solution (approx. $5 \mathrm{M} \mathrm{NaCl}$ ) upon lyophilization of the liquid phase of anaerobic resting cells of $G$. molinativorax $\mathrm{ON} 4^{\mathrm{T}}$ with molinate after $12 \mathrm{~h}$ incubation. This is believed to be the first report of ACA as an intermediate of molinate degradation,

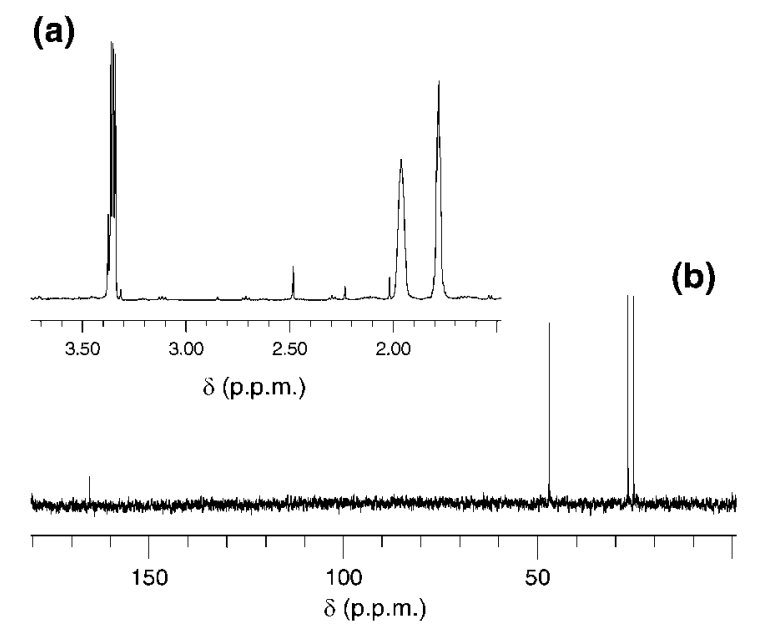

Fig. 2. ${ }^{1} \mathrm{H}-\mathrm{NMR}(\mathrm{a})$ and ${ }^{13} \mathrm{C}-\mathrm{NMR}$ (b) spectra of azepane-1carboxylic acid, obtained as described in Fig. 1 (12 h), lyophilized and resuspended in $\mathrm{D}_{2} \mathrm{O}$ prior to acquisition of spectra. The HMQC 2D-NMR technique was used to confirm C-H correlations (data not shown). 
Table 2. ${ }^{1} \mathrm{H}$ and ${ }^{13} \mathrm{C}-\mathrm{NMR}$ chemical shifts of $\mathrm{ACA}$ in saline solution $(50 \mathrm{mM} \mathrm{NaCl})$

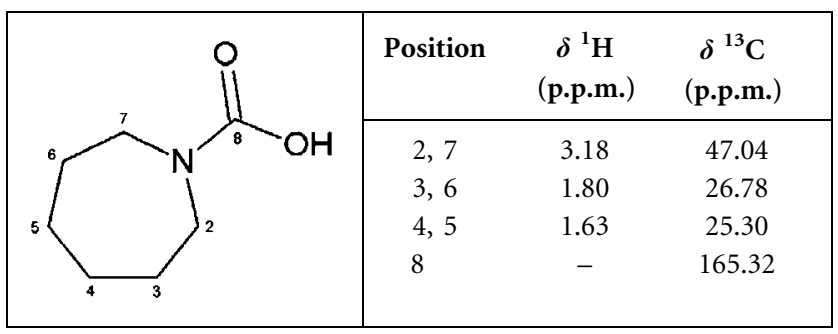

suggesting that $G$. molinativorax $\mathrm{ON} 4^{\mathrm{T}}$ may use a unique process to degrade this herbicide.

\section{Degradation of ACA by members of the mixed culture}

ACA was degraded by resting cells of Pseudomonas strains $\mathrm{ON} 1$ and $\mathrm{ON} 3$ and of G. molinativorax $\mathrm{ON} 4^{\mathrm{T}}$ after $25 \mathrm{~h}$ incubation, as this compound was not detected in the liquid phase (results not shown). ACA also supported, as carbon and nitrogen source, and in the absence of any additional organic growth factor, the aerobic growth of these organisms, with specific growth rates of $0.27 \mathrm{~h}^{-1}$ (ON1), $0.22 \mathrm{~h}^{-1}$ (ON3) and $0.13 \mathrm{~h}^{-1}$ (ON4). In contrast, S. maltophilia ON2 and A. xylosoxidans ON5 were not able to grow at the expense of ACA, either as carbon and nitrogen source, or as carbon source only. Apparently, this inability was not due to auxotrophy, as growth was not observed even in the presence of $0.2 \mathrm{~g}$ yeast extract $1^{-1}$.

McClung et al. (1994) described a microbiological process of degradation of 1-ethylsulphanyl- $N, N$-dipropylformamide (EPTC), which consisted of the hydrolysis of the thioester bond, with release of ethanethiol, dipropylamine and $\mathrm{CO}_{2}$. Hypothesizing an equivalent transformation for molinate, the organisms able to use ACA - Pseudomonas strains ON1 and $\mathrm{ON} 3$ and $G$. molinativorax $\mathrm{ON}^{\mathrm{T}}$ - would promote its decarboxylation into hexamethyleneimine (HMI), which could be further consumed as a source of carbon and nitrogen. Such a supposition was consistent with previous reports on molinate biodegradation that refer to the release of the azepane moiety in the form of HMI as a degradation product of the intermediate molinate sulphoxide (Thomas \& Holt, 1980; Imai \& Kuwatsuka, 1986). In order to confirm the hypothesis that further molinate degradation could occur via $\mathrm{HMI}$, this compound, and other commercially available possible analogues of the degradation metabolites of ACA, were assayed as growth substrates. In fact, all the isolates able to degrade ACA were also able to grow at the expense of HMI. However, in the Pseudomonas strains this process was constitutive, whereas in G. molinativorax $\mathrm{ON} 4^{\mathrm{T}}$ it was subject to ACA induction. These data suggest that ACA decarboxylation to HMI, by analogy with the metabolic pathway proposed by McClung et al. (1994), represents the next step of molinate mineralization. According to Wackett \& Hershberger (2001), HMI degradation may follow one of two alternative pathways, via caprolactam or via an open-ring aldehyde metabolite. Pseudomonas strains ON1 and ON3 were unable to grow at the expense of caprolactam, even after induction with HMI. Thus, HMI degradation in these strains may proceed via 2-hydroxy-HMI, followed by isomerization into an open-ring aldehyde metabolite and further oxidization to 6-aminohexanoic acid. In contrast, caprolactam was degraded by $G$. molinativorax $\mathrm{ON} 4^{\mathrm{T}}$, although only after successive induction with ACA and HMI. This finding hints that HMI degradation in G. molinativorax $\mathrm{ON} 4^{\mathrm{T}}$ occurs via a distinct pathway, where caprolactam is formed and further converted into 6-aminohexanoic acid. This last compound, common to both HMI degradation routes, supported the growth of both pseudomonads and of G. molinativorax $\mathrm{ON} 4^{\mathrm{T}}$.

\section{Degradation of the S-ethyl moiety of molinate}

Ethanethiol and diethyl disulphide, formed during the initial breakdown of molinate, are toxic to G. molinativorax $\mathrm{ON} 4^{\mathrm{T}}$. However, in mixed culture DC this toxic effect is avoided because $P$. chlororaphis $\mathrm{ON} 1$ and $S$. maltophilia $\mathrm{ON} 2$ are able to consume these sulphur compounds (Barreiros et al., 2003). Further investigation of the degradative performance of these two isolates revealed that $P$. chlororaphis ON1 consumed ethanethiol and diethyl disulphide at a higher rate than $S$. maltophilia ON2 (Table 3). These results were confirmed by the specific degradation rates of resting cells of these isolates with $1 \mathrm{mM}$ ethanethiol. $P$. chlororaphis $\mathrm{ON} 1$ degraded this compound at a rate approximately 10 times higher $\left[0.36 \pm 0.13 \mathrm{mg}\right.$ ethanethiol (g cell dry weight) $\left.{ }^{-1} \mathrm{~h}^{-1}\right]$ than S. maltophilia ON2 $[0.03 \pm 0.009 \mathrm{mg}$ ethanethiol (g cell dry weight $)^{-1} \mathrm{~h}^{-1}$. $P$. nitroreducens $\mathrm{ON} 3$ was also able to transform ethanethiol, although it was observed to be a conversion only, as no depletion of the added carbon occurred. In fact, approximately $75 \%$ of the added ethanethiol was converted to ethyl methyl sulphide. Given that none of the culture DC members was able to convert or to degrade the ethyl methyl sulphide, and considering the high rates of ethanethiol transformation during molinate mineralization (Barreiros et al., 2003), this product is probably not formed by $P$. nitroreducens $\mathrm{ON} 3$, when $S$. maltophilia $\mathrm{ON} 2$, and particularly $P$. chlororaphis ON1, are also present. Taken together, these results suggest that, in mixed culture DC, the ethanethiol formed during molinate cleavage can be consumed by $P$. chlororaphis $\mathrm{ON} 1$ and $S$. maltophilia ON2, although the first, as a more rapid degrader, may compete for this substrate.

\section{Evaluation of the stability of mixed culture DC}

Fig. 3 shows a putative degradation pathway for molinate and the flow of carbon, nitrogen and sulphur through the different members of culture DC, as suggested by the results obtained in the present study. According to this proposed pathway, molinate can be mineralized by G. molinativorax $\mathrm{ON}^{\mathrm{T}}$ and $P$. chlororaphis ON1. First, molinate is hydrolysed into ethanethiol and ACA by G. molinativorax $\mathrm{ON} 4^{\mathrm{T}}$, then ethanethiol is consumed by $P$. chlororaphis ON1, whereas ACA supports the growth of both strains. The behaviour of the mixture of these 
Table 3. Degradation of sulphur compounds by resting cells of mixed culture DC isolates with 0.4 mM ethanethiol

Values are the mean \pm SD of three independent experiments. SPME-GC-FID detection limit of $0.02 \mathrm{mM}$ for ethanethiol, $0.0005 \mathrm{mM}$ for diethyl disulphide and $0.02 \mathrm{mM}$ for ethyl methyl sulphide.

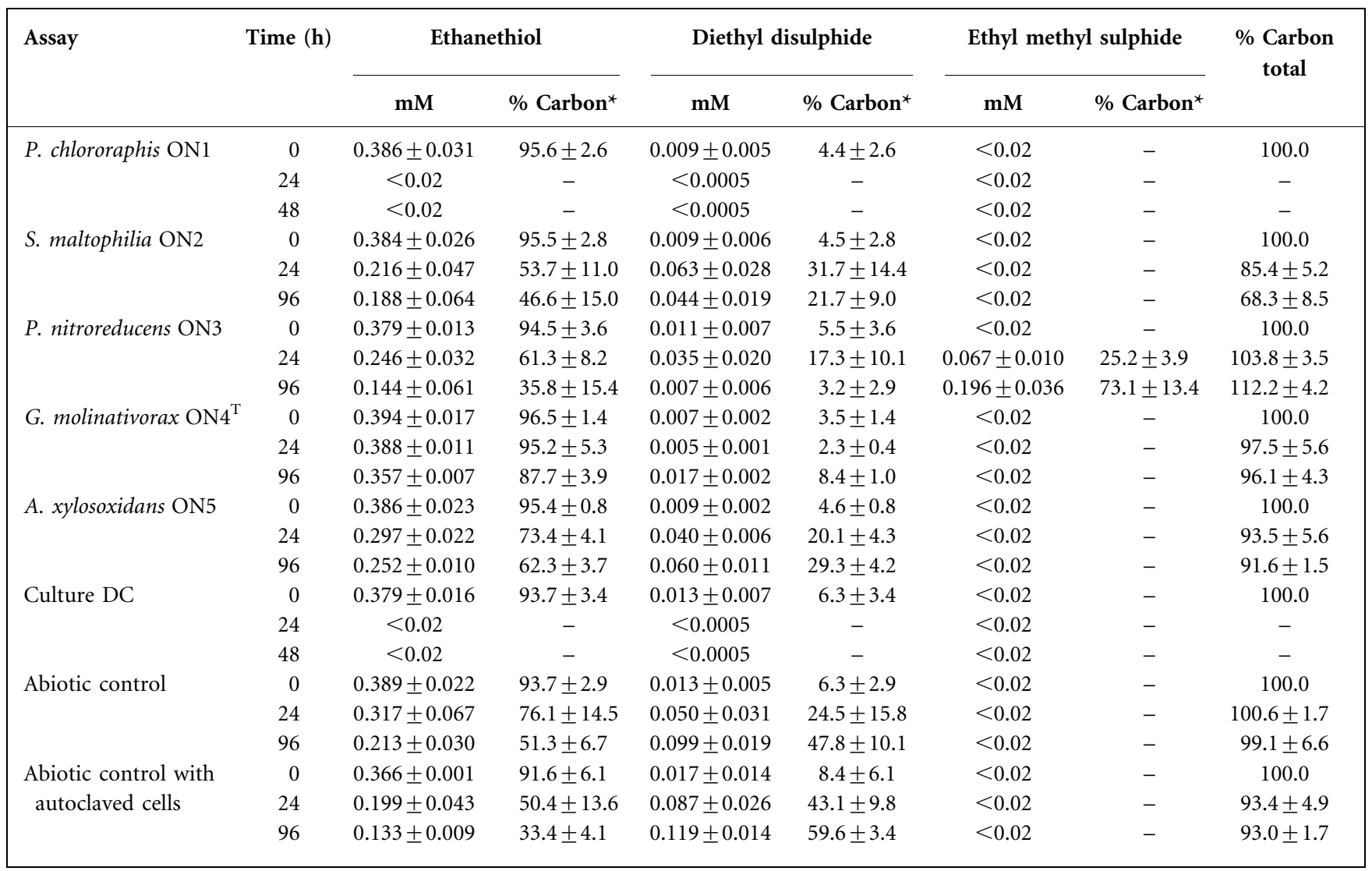

${ }^{\star}$ Percentage of carbon in the form of ethanethiol $\left(\mathrm{C}_{2} \mathrm{H}_{6} \mathrm{~S}\right)$, diethyl disulphide $\left(\mathrm{C}_{4} \mathrm{H}_{10} \mathrm{~S}_{2}\right)$ or ethyl methyl sulphide $\left(\mathrm{C}_{3} \mathrm{H}_{8} \mathrm{~S}\right)$, respectively.

isolates in the presence of $4 \mathrm{mM}$ molinate was compared with that of mixed culture DC. The analysis of Fig. 4(a, b) shows that both mixed cultures were able to grow on molinate with concomitant DOC depletion to values of $20-30 \mathrm{mg} \mathrm{l}^{-1}$. SPME-GC-FID analysis of the culture headspace and ${ }^{1} \mathrm{H}$ NMR of the respective supernatant after $72 \mathrm{~h}$ incubation revealed that neither the $S$-ethyl moiety (ethanethiol and diethyl disulphide) nor ACA accumulated in the medium (results not shown). However, the comparison of the specific growth and molinate degradation rates of the two mixed cultures revealed that, although molinate was mineralized by the mixture of $P$. chlororaphis $\mathrm{ON} 1$ and $G$. molinativorax $\mathrm{ON} 4^{\mathrm{T}}$, a possible substrate inhibition may occur. While the experimental data of growth and molinate degradation by culture DC fit a first-order kinetics $\left[0.06 \mathrm{~h}^{-1}\right.$ and $208 \mathrm{mg}$ molinate (g cell dry weight) ${ }^{-1} \mathrm{~h}^{-1}$, respectively], as described before (Barreiros et al., 2003), the data corresponding to the mixture of $P$. chlororaphis $\mathrm{ON} 1$ and $G$. molinativorax $\mathrm{ON} 4^{\mathrm{T}}$ could be described by the Haldane equation (see Methods), a conventional model of substrate inhibition. The Haldane model parameters obtained for culture DC and the mixture of $P$. chlororaphis $\mathrm{ON} 1$ and $G$. molinativorax $\mathrm{ON} 4^{\mathrm{T}}$ (with $K_{\mathrm{s}}=$
$1 \mathrm{mgl}^{-1}$ ) were, respectively, $\mu_{\max } 0.38 \mathrm{~h}^{-1}$ and $1.39 \mathrm{~h}^{-1}$, and $K_{\mathrm{i}} 102.0 \mathrm{mg} \mathrm{l}^{-1}$ and $11.5 \mathrm{mg} \mathrm{l}^{-1}$. The specific growth rate of the mixture of $P$. chlororaphis $\mathrm{ON1}$ and $G$. molinativorax $\mathrm{ON} 4^{\mathrm{T}}$ increases from $0.026 \mathrm{~h}^{-1}$ for initial molinate concentration of about $600 \mathrm{mgl}^{-1}$ up to $0.04 \mathrm{~h}^{-1}$ after consumption of approximately half the initial molinate concentration.

Molinate mineralization by culture DC seems to be comparatively more efficient, suggesting a synergistic interaction among its members. This may explain the stability of culture DC, with maintenance of its five members even after successive subculturing in mineral medium with molinate. In fact, DGGE analysis of mixed culture DC after 20 successive transfers, over a period of more than 9 months, revealed that none of the five isolates was lost (Fig. 5), as confirmed by the comparison of the sequences of each excised band with those of the pure isolates of mixed culture DC.

An important aspect concerning the stability of mixed culture DC was the presence of two organisms with no apparent function in molinate degradation. One of these isolates was $S$. maltophilia ON2, able to use ethanethiol, although at low rates, and presumably with poor growth yields. The other 


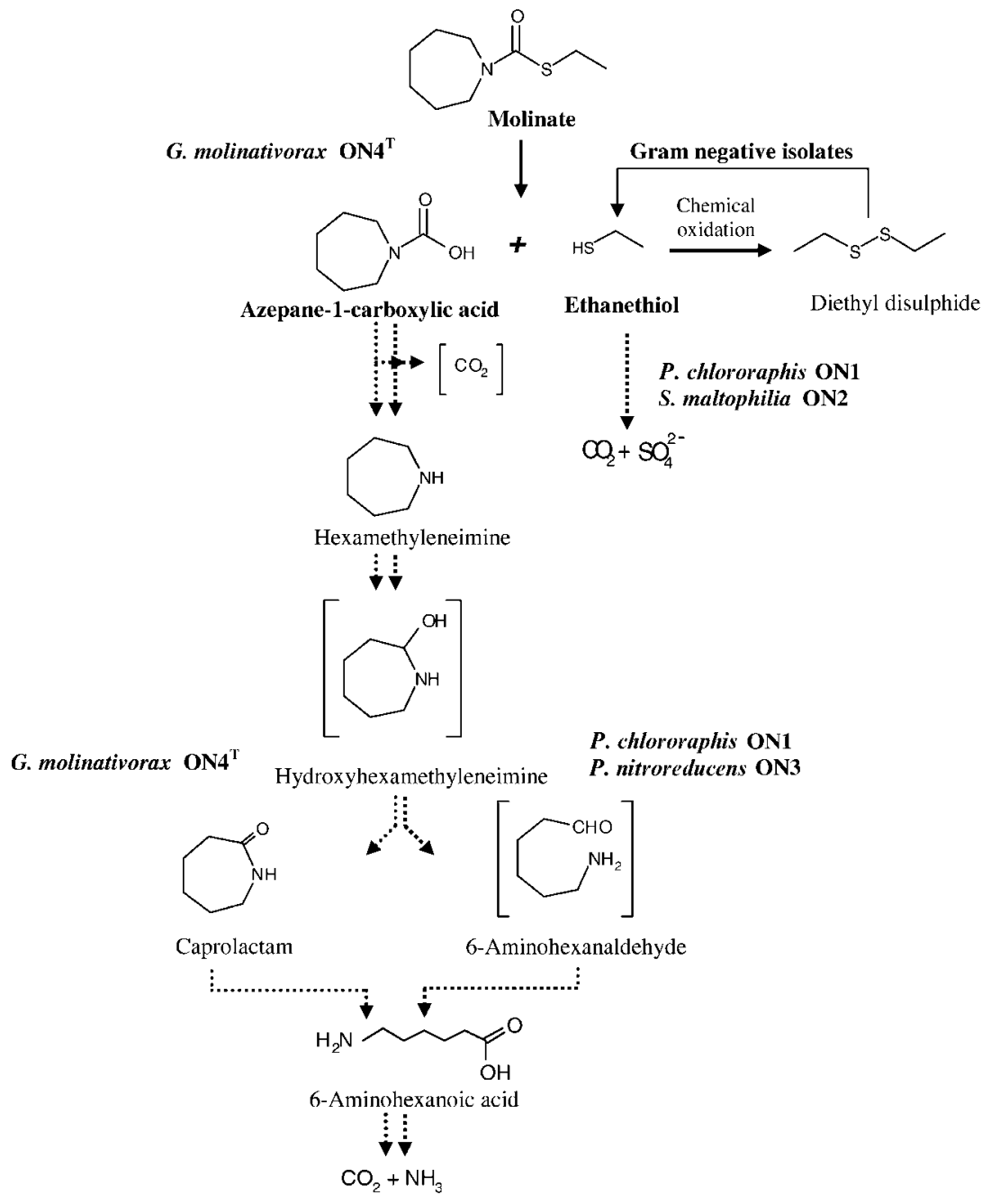

Fig. 3. Putative degradation pathway of molinate and assignment of metabolic functions of mixed culture DC members (reactions on the left, with dotted arrows, represent transformations by $\mathrm{G}$. molinativorax $\mathrm{ON} 4^{\top}$; reactions on the right, with bold dotted arrows, represent transformations by Gram-negative isolates). Compounds in brackets are presumed intermediates/products. Solid arrows represent experimentally documented reactions.

was $A$. xylosoxidans ON5, unable to grow in either the $S$-ethyl or azepane moieties of molinate. However, neither of these two isolates was lost after the successive transfers of mixed culture DC, a fact that suggests that the maintenance of these isolates in the mixed culture may be due to the use of extracellular metabolites or debris released by other mixedculture members. Alternatively, a product of partial degradation of ACA could feed these isolates. However, this hypothesis seems unlikely, because ACA metabolism is presumably intracellular, as indicated by the fact that no other metabolite was detected in the ${ }^{1} \mathrm{H}-\mathrm{NMR}$ spectra of resting cell assays of Pseudomonas strains ON1 and ON3 and G. molinativorax $\mathrm{ON} 4^{\mathrm{T}}$. The presence of subsidiary members in stable microbial communities is probably commonplace in nature and has been referred to in other biodegradation studies. For example, Pelz et al. (1999) reported the stable coexistence of a member with no apparent function in a community in a chemostat fed with 4-chlorosalicylate. The stability of consortia for long periods may be based upon a complex set of microbial interrelationships, which may include synergistic interactions involving carbon sharing, consumption of toxic metabolites, commensalism and/or competition (e.g. Pelz et al., 1999; Christensen et al., 2002; Dejonghe et al., 2003; Kato et al., 2005).

The observation that micro-organisms have evolved high catabolic potential for numerous pollutants has led to their intensive isolation and characterization, with the ultimate objective of establishing cost-effective bioremediation processes. The accumulation of knowledge on the metabolites/ catalysts/genes involved in the breakdown of different organic functional groups permitted the conclusion that different micro-organisms would degrade different compounds of the same class of chemical structure by similar catabolic routes. This allowed for creation of databases of degradative pathways (e.g. University of Minnesota Biocatalysis/Biodegradation Database, http://umbbd.ahc.umn.edu/) of great utility for previewing the catabolic routes of new isolates and/or pollutants. However, possibly due to the evolutionary potential and genetic flexibility of micro-organisms (Timmis \& Pieper, 1999), there are still descriptions of novel pathways for the degradation of pollutants for which other catabolic routes were previously known (e.g. Pieper et al., 2004). Apparently this is the case for molinate. Initially it was described as co-metabolizable by three 


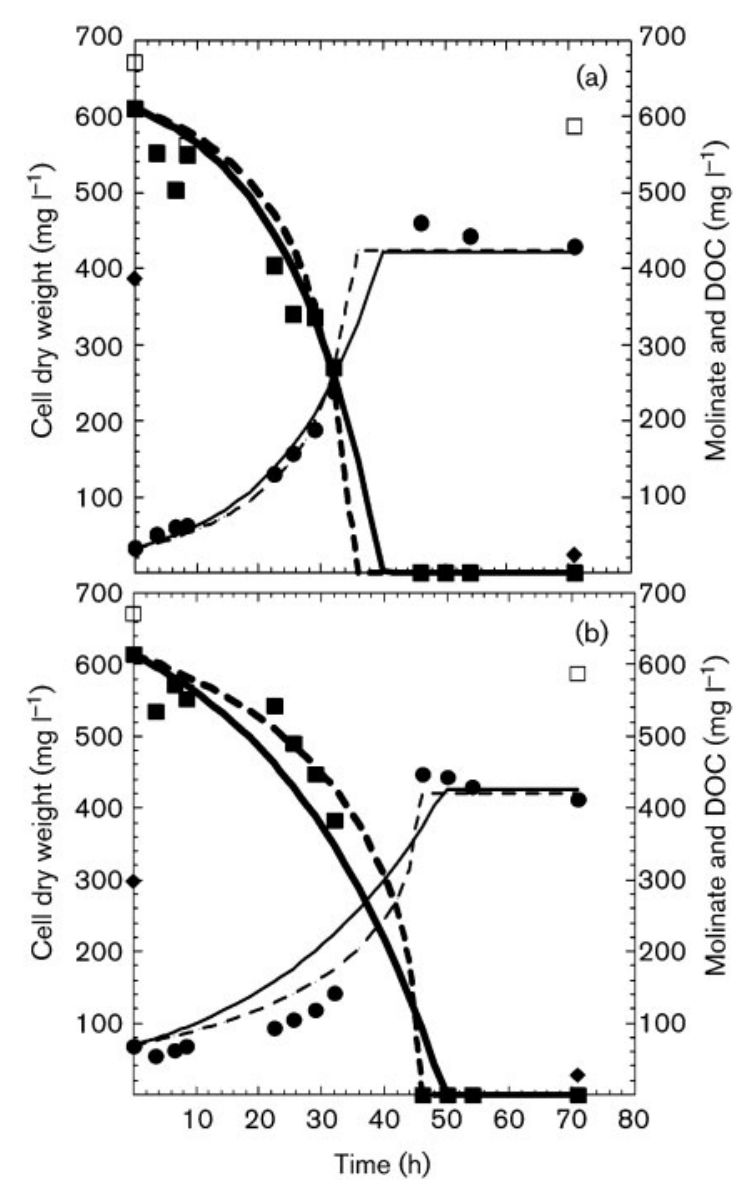

Fig. 4. Growth, molinate degradation and DOC reduction by mixed culture DC (a) and a mixture of $P$. chlororaphis ON1 and $G$. molinativorax $\mathrm{ON} 4^{\top}(\mathrm{b})$ in medium $\mathrm{B}$ with $4 \mathrm{mM}$ molinate. $\bullet$, Cell dry weight; $\mathbf{\square}$, molinate; $\boldsymbol{\nabla}$, DOC; $\square$, molinate in uninoculated medium. Fittings of a first-order kinetic model for cell dry weight and molinate are shown by full lines and bold full lines, respectively; fittings of the Haldane model for cell dry weight and molinate are shown by dashed lines and bold dashed lines, respectively.

possible degradative routes: (1) the oxidation of the sulphur atom with production of molinate sulphoxide and molinate sulphone; (2) the oxidation of the azepane moiety with production of hydroxy- and oxomolinate; or (3) the oxidation of the $S$-ethyl moiety with production of molinate alcohol and molinate acid (Soderquist et al., 1977; Thomas \& Holt, 1980; Golovleva et al., 1981; Imai \& Kuwatsuka, 1986). Among those compounds, only trace amounts of 2-oxomolinate were detected in culture DC grown with molinate as the only source of carbon, nitrogen and energy (Correia et al., 2006), supporting the hypothesis that the herbicide is degraded by this mixed culture through a different catabolic route. We (Barreiros et al., 2003; the present work) have described a new mineralizing pathway, involving the hydrolysis of the herbicide thioester bond by G. molinativorax $\mathrm{ON}^{\mathrm{T}}$ with the release of ethanethiol and ACA, which is apparently further degraded, via

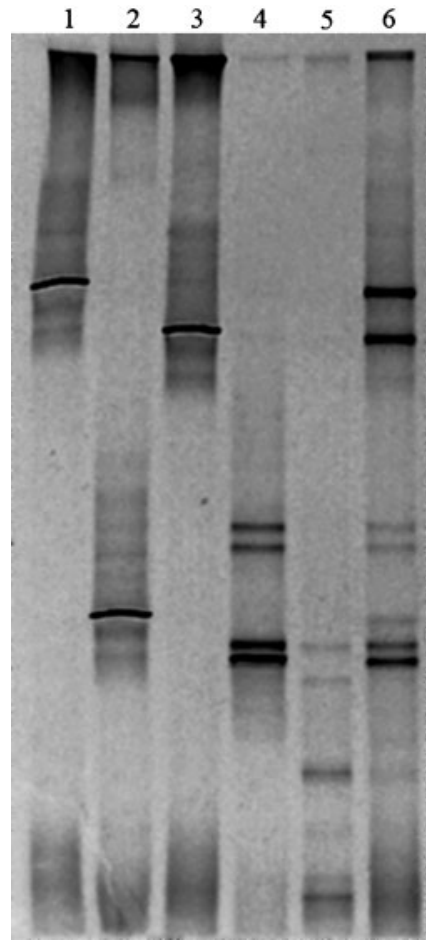

Fig. 5. DGGE profiles of mixed culture DC after 20 transfers in medium $B$ with $4 \mathrm{mM}$ molinate, and of each individual member as controls. Lanes: 1, P. chlororaphis ON1; 2, S. maltophilia ON2; 3, P. nitroreducens ON3; 4, G. molinativorax $\mathrm{ON}^{\top} ; 5$, A. xylosoxidans ON5; 6, 20th culture of mixture DC.

previously described mechanisms, by Pseudomonas strains $\mathrm{ON} 1$ and $\mathrm{ON} 3$ and G. molinativorax $\mathrm{ON} 4^{\mathrm{T}}$.

\section{ACKNOWLEDGEMENTS}

We gratefully acknowledge Herbex, Produtos Químicos SA for supplying molinate, Rui Oliveira (Faculty of Science and Technology, New University of Lisbon, Portugal) and Rui Boaventura (LSRE-FEUP) for helpful analysis of the experimental data, and Isabel Henriques and António Correia (Department of Biology, University of Aveiro, Portugal) for their advice on DGGE analysis. This work was financially supported by Fundação para a Ciência e a Tecnologia through FEDER funding (project POCTI/P/BIO/12193/1998 and grants SFRH/BD/4558/2001 and SFRH/BD/22615/2005).

\section{REFERENCES}

Barreiros, L., Nogales, B., Manaia, C. M., Ferreira, A. C. S., Pieper, D. H., Reis, M. A. \& Nunes, O. C. (2003). A novel pathway for mineralization of the thiocarbamate herbicide molinate by a defined bacterial mixed culture. Environ Microbiol 5, 944-953.

Cashion, P., Holder-Franklin, M. A., McCully, J. \& Franklin, M. (1977). A rapid method for the base ratio determination of bacterial DNA. Anal Biochem 81, 461-466.

Christensen, B. B., Haagensen, J. A., Heydorn, A. \& Molin, S. (2002). Metabolic commensalism and competition in a two-species microbial consortium. Appl Environ Microbiol 68, 2495-2502. 
Correia, P., Boaventura, R. A., Reis, M. A. \& Nunes, O. C. (2006). Effect of operating parameters on molinate biodegradation. Water Res 40, 331-340.

De Souza, M. L., Newcombe, D., Alvey, S., Crowley, D. E., Hay, A., Sadowsky, M. J. \& Wackett, L. P. (1998). Molecular basis of a bacterial consortium: interspecies catabolism of atrazine. Appl Environ Microbiol 64, 178-184.

Dejonghe, W., Berteloot, E., Goris, J., Boon, N., Crul, K., Maertens, S., Höfte, M., De Vos, P., Verstraete, W. \& Top, E. M. (2003). Synergistic degradation of linuron by a bacterial consortium and isolation of a single linuron-degrading Variovorax strain. Appl Environ Microbiol 69, $1532-1541$.

Dias, B. \& Weimer, B. (1998). Purification and characterization of L-methionine $\gamma$-lyase from Brevibacterium linens BL2. Appl Environ Microbiol 64, 3327-3331.

Feigel, B. J. \& Knackmuss, H. J. (1993). Syntrophic interactions during degradation of 4-aminobenzenesulfonic acid by a two-species bacterial culture. Arch Microbiol 159, 124-130.

Golovleva, L. A., Finkelstein, Z. I., Popovich, N. A. \& Skriabin, G. K. (1981). Transformation of ordram by microorganisms. Izv Akad Nauk SSSR Biol 3, 348-358.(in Russian)

Hall, T. A. (1999). BioEdit: a user-friendly biological sequence alignment editor and analysis program for Windows 95/98/NT. Nucleic Acids Symp Ser 41, 95-98.

Hay, A. G., Dees, P. M. \& Sayler, G. S. (2001). Growth of a bacterial consortium on triclosan. FEMS Microbiol Ecol 36, 105-112.

Henriques, I. S., Alves, A., Tacão, M., Almeida, A., Cunha, A. \& Correia, A. (2006). Seasonal and spatial variability of free-living bacterial community composition along an estuarine gradient (Ria de Aveiro, Portugal). Estuar Coast Shelf Sci 68, 139-148.

Imai, Y. \& Kuwatsuka, S. (1986). Metabolic pathways of the herbicide molinate in four strains of isolated soil microorganisms. J Pestic Sci 11, 245-251.

Kato, S., Haruta, S., Cui, Z. J., Ishii, M. \& Igarashi, Y. (2005). Stable coexistence of five bacterial strains as a cellulose-degrading community. Appl Environ Microbiol 71, 7099-7106.

Manaia, C. M., Nogales, B., Weiss, N. \& Nunes, O. C. (2004). Gulosibacter molinativorax gen. nov., sp. nov., a molinate degrading bacterium, and classification of 'Brevibacterium helvolum' DSM 20419 as Pseudoclavibacter helvolus gen. nov., sp. nov. Int J Syst Evol Microbiol 54, 783-789.
McClung, G., Dick, W. A. \& Karns, J. (1994). EPTC degradation by isolated soil microorganisms. J Agric Food Chem 42, 2926-2931.

Muyzer, G., de Waal, E. C. \& Uitterlinden, A. G. (1993). Profiling of complex microbial populations by denaturing gradient gel electrophoresis analysis of polymerase chain reaction-amplified genes coding for $16 \mathrm{~S}$ rRNA. Appl Environ Microbiol 59, 695-700.

Nojiri, H., Shintani, M. \& Omori, T. (2004). Divergence of mobile genetic elements involved in the distribution of xenobiotic-catabolic capacity. Appl Microbiol Biotechnol 64, 154-174.

Pelz, O., Tesar, M., Wittich, R. M., Moore, E. R. B., Timmis, K. N. \& Abraham, W. R. (1999). Towards elucidation of microbial community metabolic pathways: unravelling the network of carbon sharing in a pollutant-degrading bacterial consortium by immunocapture and isotopic ratio mass spectrometry. Environ Microbiol 1, 167-174.

Pieper, D. H., Martins dos Santos, V. A. P. \& Golyshin, P. N. (2004). Genomic and mechanistic insights into the biodegradation of organic pollutants. Curr Opin Biotechnol 15, 215-224.

Soderquist, C. J., Bowers, J. B. \& Crosby, D. G. (1977). Dissipation of molinate in a rice field. J Agric Food Chem 25, 940-945.

Sorensen, S. R., Ronen, Z. \& Aamand, J. (2002). Growth in coculture stimulates metabolism of the phenylurea herbicide isoproturon by Sphingomonas sp. strain SRS2. Appl Environ Microbiol 68, 3478-3485.

Thomas, V. M. \& Holt, C. L. (1980). The degradation of $\left[{ }^{14} \mathrm{C}\right]$ molinate in soil under flooded and nonflooded conditions. J Environ Sci Health B 15, 475-484.

Timmis, K. N. \& Pieper, D. H. (1999). Bacteria designed for bioremediation. Trends Biotechnol 17, 200-204.

Top, E. M., Springael, D. \& Boon, N. (2002). Catabolic mobile genetic elements and their potential use in bioaugmentation of polluted soils and waters. FEMS Microbiol Ecol 42, 199-208.

Tsuda, M., Tan, H. M., Nishi, A. \& Furukawa, K. (1999). Mobile catabolic genes in bacteria. J Biosci Bioeng 87, 401-410.

Wackett, L. P. \& Hershberger, C. D. (2001). Metabolic Logic and Pathway maps. In Biocatalysis and Biodegradation: Microbial Transformation of Organic Compounds, pp. 135-155. Washington, DC: American Society for Microbiology.

Edited by: H. L. Drake 